\title{
TESTAMENTO Y TIEMPO: HISTORIA Y DERECHO EN EL DOCUMENTO DE ÚLTIMA VOLUNTAD
}

\author{
Soledad GÓMEZ NAVARRO \\ Universidad de Córdoba
}

\section{RESUMEN}

Desde la siempre conveniente y fructífera interdisciplinariedad, el presente artículo estudia, aliando Historia y Derecho -Historia del Derecho singularmente-, la noción de testamento y sobre todo su evolución histórica. Fundamentalmente fuentes jurídicas pasadas y presentes ayudan a trazar la trayectoria de dicho instrumento jurídico dispositivo desde su nacimiento hasta, su definitiva conformación en la época moderna, analizándose las distintas sucesivas aportaciones observadas en la construcción de su concepto, y sus interpretaciones. Junto a presentar el testamento como producto histórico -sociohistórico mejor dicho-, cuyo resultado final es fruto de su adaptación y adecuación a las necesidades colectivas, quizás la virtualidad más significativa de esta contribución sea la de acercarse a la realidad jurídica desde el específico campo de la historia.

Palabras claves: España, Historia Moderna, Testamentos.

\section{$\underline{\text { SUMMARY. }}$}

This article deals with the concept of will and above all its historical evolution, linking History and Laws -in particular History of Laws- since the always convenient and fruitful interdisciplinarity. Mainly past and present legal sources help us to draw the lines of that legal device from its birth to its final form in the modern times, analysing the different and consecutive contributions taken into account in the constitution of its concept, as well as its interpretations. In addition to presenting the will as a historical product -or, better said, socio historical- whose final result is due to its adaptation and fitting to collective needs, the most meaningful feature of this contribution will probably be its approach to the legal fact since the particular field of the history.

Keywords: Spain, Modern Story, Wills. 


\section{INTRODUCCIÓN}

Objeto de sesudos estudios por parte de tratadistas y juristas, el testamento no es aventajado por ningún acto jurídico "en la importancia de los efectos que está destinado a producir, en la solemnidad de las formas que lo acompañan ni en el particular cuidado con que la ley atiende a cumplir la suprema voluntad del difunto" ${ }^{\prime 1}$. Esta institución, tan esencial en el Derecho moderno, pero también una de las mas lentamente elaboradas en la Historia del Derecho, es núcleo específico del Derecho de Sucesiones o Derecho Hereditario, sección del Derecho privado "constituida por el conjunto de normas que regulan el destino que ha de darse a las relaciones jurídicas de una persona fisica cuando ésta muere; y rige también la creación de relaciones jurídicas nuevas, cuyo resurgir estaba supeditado a la muerte de dicha persona" ${ }^{2}$.

En las primeras sociedades no existió, sin embargo, verdadera sucesión testamentaria. Fue en el Derecho romano donde ésta adquirió todo su desenvolvimiento e importancia, aunque los romanos no se elevaron desde el comienzo de su historia a una concepción como la del testamento y la libertad de testar, incomprensible, por lo demás -y según Ihering-, para infinidad de pueblos. Las formas de disposición hereditaria de la época de las Doce Tablas constituyen, más que un verdadero testamento, una especie de adopción hereditaria o institución contractual, y parecen representar una fase intermedia o de transición entre la primitiva sucesión legítima y la sucesión propiamente testamentaria. No obstante, esta primera época consolidaría una importante cualidad del testamento posterior, ya que el derecho pretorio dio al testamento romano el carácter de acto unilateral con que ha pasado al Derecho moderno. En éste último, empero, la institución presenta caracteres y tendencias que le dan fisonomía propia, distinta de la del testamento romano. Figuran entre aquéllos tres rasgos fundamentales de distinción: Primero, supresión de la necesidad de la institución de heredero, esencial al testamento romano, pero no, y como se ha comentado ${ }^{3}$, condición jurídica sine qua non del acta testamentaria moderna -" ¿Sería válido un testamento que no contuviera institución de heredero? Según nuestras leyes es perfectamente admisible esta posibilidad[...]"4-. Segundo, difusión de la forma pública notarial, que ha permitido simplificar mucho las formalidades requeridas por las legislaciones antiguas. Tercero, por último, admisión del testamento ológrafo creado por el Código de Napoleón y aceptado por la mayoría de las regulaciones modernas ${ }^{5}$.

Como se ha indicado, el objetivo principal de este trabajo es presentar cómo se ha ido conformando el documento de última voluntad hasta la Edad Moderna desde los distintos ordenamientos jurídicos existentes y vigentes a lo largo del tiempo, construcción producto precisamente de la adaptación y adecuación de aquel instrumento dispositivo a las necesidades sociales -históricas en suma- imperantes en cada momento. 


\section{NOCION DE TESTAMENTO.}

Un repaso sobre la evolución histórica de su concepto como la que abordaremos, indica que durante mucho tiempo la cuestión más debatida fue identificar el rasgo que confería validez al testamento -sucesión de distintas interpretaciones sobre si su única garantía jurídica estribaba en la necesidad o no de instituir heredero-. Sin embargo, el actual ordenamiento legal, superando esa vieja polémica, ha centrado su mayor interés en señalar la naturaleza y auténtica esencia del documento. En este sentido, los pronunciamientos jurídicos contemporáneos coinciden en subrayar la principal finalidad de ese acto libre, a saber, expresar la voluntad del otorgante respecto a lo que desea que se haga con lo propio después de su muerte, y han concentrado los mayores esfuerzos legislativos en desarrollar aspectos concretos de esa idea nuclear.

Esta última orientación halla su más lejano precedente en la ya clásica definición de Modestino: "Testamentum est voluntatis nostrae iusta sententia de eo quod quis post mortem suam fieri velit" ${ }^{\prime \prime}$. Se prolonga en la del proyecto de Código español de 1851, definidor del testamento como "acto solemne y esencialmente revocable por el que dispone el hombre de todo o parte de sus bienes para después de su muerte en favor de una o más personas"7. Y se plasma definitivamente en nuestro Código civil, cuyo artículo 667 expresa que "el acto por el cual una persona dispone para después de su muerte de todos sus bienes o de parte de ellos, se llama testamento"8. De esta definición y de las fórmulas de otros autores, resumibles fundamentalmente en dos tipos, definiciones de sentido muy genérico que continúan la huella de Modestino, considerando el testamento como el acto por el cual el hombre manifiesta su última voluntad para que ésta sea cumplida después de su muerte, y de contenido extenso y detallado, apartado en el que destaca la de Mucius Scaevola, para quien el testamento es un "acto espontáneo, personal, solemne y revocable, por virtud del cual una persona, según su arbitrio y los preceptos de la ley, dispone, para después de su muerte, tanto de su fortuna como de todo aquello que, en la esfera social en que vive, puede y debe ordenar en pro de sus creencias y de las personas que a él estén unidas por cualquier lazo de intereses" ${ }^{9}$, se deduce que el testamento está dotado básicamente de tres rasgos cuya presencia es indispensable,', según Castán, para su auténtica validación:

Es un acto por el cual se dispone. En consecuencia, no es verdadero testamento el que, aun presentando forma externa de tal, pueda suscitar duda sobre si constituye un simple esbozo o esquema y no un acto definitivo; y asimismo no tendrá eficacia de verdadera disposición testamentaria aquella por la que el otorgante se limita a aconsejar o rogar respecto al destino de sus bienes. 
Por el que se dispone, además, para después de la muerte, lo cual supone, por consiguiente, que se manifiesta con claridad esa intención de testar, es decir, de disponer para después de la defunción.

Y por el que, sustancialmente, se realiza disposición de bienes, si bien accidentalmente puede contener no sólo declaraciones que tengan relación directa con éstos, sino también otras de carácter personal y familiar.

Este perfil sobre la esencia del testamento se completa con la relación de los caracteres que le confieren su naturaleza jurídica. El Código civil la sanciona, expresa o virtualmente, con la incorporación de seis atributos indispensables y muy concretos, que completan el concepto legal del testamento:

Es un negocio jurídico mortis causa $y$, como tal, unilateral ${ }^{10}$; individual, pues ha de ser otorgado por una sola persona, rechazándose así los antiguos testamentos mancomunados ${ }^{11}$; personalísimo, por cuanto no puede dejarse su formación, en todo ni en parte, al arbitrio de un tercero, ni hacerse por medio de comisario o mandatario ${ }^{12}$; libre, es decir, hecho sin violencia, dolo ni fraude, carácter, empero, común a todos los actos jurídicos ${ }^{13}$; formal o solemne, por cuanto es imprescindible que revista las garantías y solemnidades fijadas por ley para no incurrir en la nulidad del acto $^{14}$; y esencialmente revocable, hasta el punto de ser nulas las antiguas cláusulas derogatorias o ad cautelam ${ }^{15}$.

Cualquier análisis que se plantee prestar atención al concepto de testamento, como es el caso, debe mencionar, al menos someramente, el contenido que normalmente lo cierra: $\mathrm{El}$ de las especies o clases de testamentos.

Es difícil realizar una clasificación racional de los testamentos. Las varias divisiones que de ellos hacen los códigos y los autores adolecen de poca precisión o son arbitrarias. Lo habitual es que se distingan en públicos y privados o, como dicen otros, en públicos, privados y mixtos.

Los públicos se definen porque la declaración de voluntad ha sido hecha ante una persona investida de carácter oficial, notarios, jueces, autoridades administrativas, militares o eclesiásticas. Los privados son aquéllos en que el testador interviene solo en la realización del acto, sin que presten asistencia ni funcionario ni testigos, como sucede en el testamento ológrafo. Y los mixtos, los que participan de las dos categorías anteriores, como el cerrado y los testamentos hechos ante testigos aunque sin funcionario público, si bien, en opinión de Isábal, este grupo intermedio es artificial, por lo que deben separarse las variedades que lo constituyen y asimilarlas a una u otra de las dos opuestas formas primordiales citadas, esto es, se incluirían en el grupo de testamentos públicos todas aquellas actas de última voluntad cuya formalización exige concurso de un 
funcionario, sin mayor distinción, y se considerarían subespecies del testamento público, el abierto y el cerrado o secreto.

Desde otro punto de vista, los testamentos se dividen también en comunes $\mathbf{u}$ ordinarios y especiales o privilegiados.

Los primeros son los que la ley regula para que sean otorgados en circunstancias y con las formalidades normales; los segundos, los que se establecen para situaciones excepcionales, cuando no es posible hacer uso de las formas comunes de testar, y requieren unas veces más solemnidades y otras menos que los ordinarios. Atendiendo a esta última idea, algunos autores subdividen los especiales según el grado de su solemnidad respecto a los ordinarios, pero otros los clasifican conforme a los motivos que fundamentan su excepcionalidad, resultando básicamente tres categorías independientes y una conjunta de éstas: Por razón de la persona del testador -testamentos de loco, sordomudo, ciego, hecho en lengua extranjera y el otorgado en inminente peligro de muerte-; del lugar de dación -el marítimo y el hecho en país extranjero-; y del tiempo -ejecutado en momento de epidemia-. El testamento militar, por su parte, representa la combinación de las tres posibilidades o circunstancias indicadas ${ }^{16}$.

Por su aplastante presencia en la cartografía testamentaria hispana -al menos cordobesa $\mathrm{y}$, que nos conste, también meridional por extenso-, nos detenemos brevemente en las condiciones exigidas para el otorgamiento de los llamados testamentos abiertos o nuncupativos individuales ${ }^{17}$.

Según el Código civil vigente, "es abierto el testamento siempre que el testador manifiesta su última voluntad en presencia de las personas que deben autorizar el acto, quedando enteradas de lo que en él se dispone." ${ }^{18}$. Esta definición indica que esta modalidad testamentaria precisa para su otorgamiento de la intervención de personas distintas del testador que autorizan el acto y reciben la declaración de su voluntad, conociendo su contenido. Su reglamentación específica exige que sea otorgado ante "[...]Notario hábil para actuar en el lugar del otorgamiento, y tres testigos idóneos que vean y entiendan al testador, y de los cuales uno, a lo menos, sepa y pueda escribir" ${ }^{19}$. Combinando este último requisito y la específica definición anterior, podríamos considerar como concepto legal del testamento común abierto, el otorgado ante Notario y tres testigos, en el que el testador manifiesta su última voluntad en presencia de dichas personas, que quedan enteradas de lo que en él se dispone ${ }^{20}$.

Como se ve, es la garantía de disponer el rasgo que confiere verdadera entidad jurídica al testamento y la característica que se convierte en su principal finalidad. En esa capacidad de disponer entra 'todo', y en este 'todo', también dos contenidos especiales: El alma y los pobres. Naturalmente, también el Código civil contempla la ordenación de estos dos posibles beneficiarios. 
La primera designación queda recogida en el art $^{\circ} 747$, cuyo tenor no sólo salvaguarda los intereses y respectivas soberanías de las dos instituciones afectadas por esa decisión -es decir, la Iglesia y el Estado ${ }^{21}$-, sino que también regula expresamente dicha determinación y su reparto: "Si el testador dispusiere del todo o parte de sus bienes para sufragios $y$ obras piadosas en beneficio de su alma, haciéndolo indeterminadamente $y$ sin especificar su aplicación, los albaceas venderán los bienes $y$ distribuirán su importe, dando la mitad al Diocesano para que lo destine a los indicados sufragios y a las atenciones y necesidades de la Iglesia, y la otra mitad al Gobernador civil correspondiente para los establecimientos benéficos del domicilio del difunto, y en su defecto, para los de la provincia" $^{\prime 22}$.

La segunda posibilidad plasmada en el art" 749 , indica que "las disposiciones hechas a favor de los pobres en general, sin designación de personas ni de población, se entenderán limitadas a los del domicilio del testador en la época de su muerte, si no constare claramente haber sido otra su voluntad. La calificación de los pobres y la distribución de los bienes se harán por la persona que haya designado el testador, en su defecto por los albaceas, y, si no los hubiere, por el Párroco, el Alcalde y el Juez municipal, los cuales resolverán, por mayoría de votos, las dudas que ocurran. Esto mismo se harán cuando el testador haya dispuesto de sus bienes en favor de los pobres de una parroquia o pueblo determinado" ${ }^{23}$.

El que la expresión de su voluntad hecha por el disponente ante notario $y$ testigos instrumentales sea el requisito verdaderamente característico del testamento abierto, es también la distinción que lo separa del ológrafo y del cerrado.

La legislación anterior al Código civil suponía que el testador había de manifestar su última disposición de viva voz -de ahí lo de 'nuncupativo', pero el actual ordenamiento jurídico admite que dicha manifestación pueda hacerse verbalmente o por escrito ${ }^{24}$. La culminación de este otorgamiento queda vinculada inexcusablemente a la realización de tres fases unidas a esa primera, que constituye la expresión de la voluntad:

Primera, redacción del testamento, apartado del que no podrán faltar, entre otros requisitos, dos específicos de este tipo de testamento: Identificación del testador y constatación de su capacidad para testar.

Manifestada su última voluntad por el testador, el notario redactará el testamento con arreglo a dicha voluntad, si bien en el caso de que no sea expresada adecuadamente deberá dar forma jurídica a la voluntad testamentaria ${ }^{25}$. 
El notario cumplirá también con los requisitos generales que para la redacción de instrumentos públicos impone la legislación notarial, pero, además, el Código impone como propios de este testamento los siguientes: Consignación en éste del "[...] lugar, año, mes, día y hora de su otorgamiento[...]"26; el notario "dará fe" al final del testamento de haberse cumplido todas las formalidades exigidas y de conocer al testador -o a los testigos de conocimiento en su caso-; y hará constar la muy importante aclaración de que " [...] a su juicio, se halla el testador con la capacidad legal necesaria para otorgar testamento" ${ }^{27}$.

De todos ellos, quizás pueda resultar curiosa la imprescindible inclusión de la hora, pero este requisito responde a uno de los caracteres fundamentales del testamento, el de su revocabilidad, como ya vimos, pues, como también sabemos, la disposición de última voluntad puede ser variada en cualquier momento por el testador y podría darse' la circunstancia de que en el mismo día una persona otorgara varios testamentos, en cúyo caso sólo la expresión de la hora es el único medio de saber cuál es la última disposición testamentaria $\mathrm{y}$, por tanto, la contenedora de la voluntad del causante ${ }^{28}$.

La segunda fase la constituye la aprobación del testamento. Una vez redactado conforme a la voluntad de otorgante, el notario lo leerá en yoz alta en presencia de los testigos para que manifieste aquél si su contenido es la expresión de su última voluntad, es decir; si el testamento es conforme con ésta ${ }^{29}$. Si es así, será firmado en el acto por el testador y los testigos que puedan hacerlo. Si el testador declara que no sabe o no puede firmar, lo hará por él, y a su ruego, uno de los testigos instrumentales presentes -tres, como obliga la ley en casos normales, cinco cuando concurre cualquier circunstancia especial ${ }^{30}-\mathbf{u}$ otra persona, dando fe de ello el notario. Lo mismo se hará cuando alguno de los testigos no pueda firmar ${ }^{31}$.

Y la tercera y última fase, la unidad del acto, requisito este último que, procedente de las especiales características del testamento romano en sus formas más antiguas y recogido en nuestro Código civil siguiendo la tradición romanista presente en las Partidas -todas las formalidades se practicarán "[...]en un solo acto, sin que sea lícita ninguna interrupción, salvo la que pueda ser motivada por algún accidente pasajero ${ }^{\prime 32}$-, ha sido interpretado por la jurisprudencia de modo racional y circunscrito a lo que propiamente constituye el otorgamiento: Lectura, expresión por el testador de su conformidad, y firma ${ }^{33}$.

Terminan así las cuestiones relativas al aspecto externo e interno del testamento. El desarrollo de su estructura viene determinado por el contenido concreto de ese documento, destinado fundamentalmente, como sabemos, a recoger la plasmación de la voluntad del causante. 
Como todas las escrituras notariales, también ésta exige un orden formal de composición. Ordinariamente lleva un proemio que constituye la parte expositiva, dedicada a las declaraciones del testador que consigna el notario sin responder de su veracidad; parte central o dispositiva, rellenada con el tenor de las cláusulas -exposición imperativa de su voluntad para que se cumpla en el futuro- y nombramientos de ejecutores testamentarios y herederos; y escatocolo, cumplimiento de formalidades externas -data $y$ validación- ${ }^{34}$.

\section{EVOLUCIÓN HISTÓRICA.}

Del presente al pasado. Una vez examinado el concepto y los caracteres actuales del testamento abierto individualizado, analicemos ahora los pasos que determinan su proceso de conformación, una trayectoria surcada por el peso de factores de muy distinto signo, pero cuya interrelación, no por más evidente, debe quedar menos manifiesta:

Cronológicos, labor de varios siglos que arrancan en la época imperial y desembocan en la modernidad. Históricos, avatares comunes al Occidente europeo: Aparición del Cristianismo, caída de la estructura política imperial, invasiones, emersión del feudalismo, articulación del Estado moderno; o específicos del solar hispánico: Lastre de la Reconquista. Culturales y políticos sobre todo: Encuentro combinado de Iglesia y Estado, dos grandes estructuras que se repartirán esferas de poder e influencias en la larga "Edad Clásica" europea.

Como dijimos, desde que surgió la escuela histórica del Derecho, muy pocos juristas dudan ya de que el testamento es un producto histórico perteneciente al Derecho civil, y de que ese instrumento notarial afecta, por encima de otra consideración, a los intereses del testador y a los de su heredero, pero también a la sociedad toda. Mostrar, pues, cómo se produce la consolidación del ordenamiento jurídico que enmarca la ejecución formal del acto testamentario; la elaboración de una filosofía que justifique el sentido contenido en la estructura del testamento; y la consecución de un ámbito legal que regule el ejercicio de la práctica testamentaria durante el Antiguo Régimen, periodo que obviamente nos interesa, es la principal tarea, por tanto, de este punto ${ }^{35}$.

Por lo demás, si bien el testamento abierto o nuncupativo constituye "la más antigua forma de testar" ${ }^{13}$, una de las más usuales ${ }^{37}$, la que "más comúnmente se hace ${ }^{138}$, y la que, en puridad, puede considerarse como único testamento notarial ${ }^{39}$, es obvio que esas cualidades no impiden su comunión con la noción, caracteres jurídicos y evolución histórica del testamento propiamente dicho, de cuyo tronco común participa y del que sólo se distancia para acentuar su personalidad en los rasgos que dan sentido a su específica ejecución; ejecución, resultado también, y a su vez, 
de unas fases de conformación histórica propia, cuyas principales etapas vamos a cubrir.

Aunque hasta ahora no hayamos hecho alusión expresa a esta relación, es evidente que el origen del concepto de testamento quedó vinculado, desde el principio y para siempre -su misma evolución se acompasa al ritmo de esta ligazón-, a la acumulación de un patrimonio, a la posibilidad de disponer de él en favor de alguien, y a la decisión de efectivamente así hacerlo, porque, como subrayó hace tiempo Gutiérrez Fernández ${ }^{40}$, la testación o testamentifacción es una consecuencia de la propiedad y tiene su origen en ella, y esta dependencia es el interesante dato básico que importa subrayar de entrada y desde ahora.

En este sentido, si bien, y como veremos, en su primera acepción, y sobre todo en su posterior evolución, el surgimiento del testamento vino determinado por el Derecho sucesorio romano, y más concretamente por el postclásico y el justinianeo, los especialistas han demostrado que la elaboración y conformación del concepto de testamento, implicado por tanto en la regulación jurídica de la propiedad que la cultura romana legará a Occidente, es resultado del desarrollo del propio derecho romano, y de sucesivas aportaciones históricas, algunas de las cuales ya se apuntaron: Aparición del Cristianismo, acomodación a la praxis jurídica de los invasores, crisis social altomedieval, recuperación posterior de la tradición romana. Éstas, entre otras, fueron responsables de que la práctica testamentaria del Derecho sucesorio romano sufriera una alteración, bien por enriquecimiento de algunos elementos o supresión de otros, pero, en todo caso, por modificación de su estructura; experimentara un retroceso en su aplicación y desarrollo al contraponer los conceptos jurídicos clásicos a los vulgares; se adaptara a la presencia del Derecho germánico; y coexistiera con un proceso de cristianización que incidirá en las tradiciones romano-vulgares y germánicas. Ahora bien; es absolutamente defendido que fue en el Derecho hereditario romano donde se definió y consolidó el acto del otorgamiento. En dicha regulación se distinguen tres etapas, dominadas cada una de ellas por la difusión de varias formas de testamento ${ }^{41}$ :

Una primera, cuya norma sucesoria estuvo regida por el "ius civile romanorum" apoyado en las bases de la propiedad quirtaria y de la familia agniticia creada y sostenida por la idea de "potestas". Otra segunda, prolongada durante la época clásica, en la que, junto a la normativa sucesoria del "ius civile", el pretor moldea un Derecho sucesorio honorario permitiendo el disfrute de la sucesión a los unidos al difunto por vínculo de consanguinidad. Y la última, también la más presente por su influencia en la trayectoria posterior, la del Derecho justinianeo, en que desaparece la dualidad de creación normativa propia de las dos etapas anteriores, y el Derecho sucesorio ofrece las mismas características que han pasado, a 
través de la recepción del Derecho común (siglos XII-XIII), a los códigos modernos.

En consonancia, pues, con esos supuestos, desde las primitivas formas jurídicas de regular la posibilidad de heredar hasta la recepción del Derecho común, pasando por las modificaciones bajoimperiales y altomedievales, el concepto de testamento y su contenido sufrirá una importante evolución, algunos de cuyos principales hitos son los siguientes $^{42}$ :

\section{Etapa del Derecho romano arcaico y preclásico:}

Probablemente, la posibilidad que contemplaba de que aquellos individuos que no tuvieran hijos destinaran sus bienes a un extraño institución de la arrogatio-, constituya el precedente más remoto del testamento y señale el inicio de su aparición, ya que ese instrumento jurídico permitía la conversión de ese extraño en miembro de la familia y, por tanto, en heredero del testador.

\section{2. Época clásica del Derecho romano:}

Se perfila el concepto del testamento, entendido, según la definición ulpianea, como toda manifestación legítima de voluntad, hecha con las debidas solemnidades, para que surta efecto después de la muerte. La capacidad de testar se denomina testamenti factio activa, y la de recibir por testamento testamenti factio pasiva. Desaparecen antiguas modalidades de testamentum calatis comitiis -ante el pueblo- y testamentum in procintu declaración hecha por el "pater familias" entre sus compañeros antes de iniciar la batalla- y perdura la forma ordinaria de testar -la mancipatoria, es decir, mediante la solemnidad del testamentum per aes et libram-, en su forma oral o nuncupativa, en la cual el testador declara de viva voz su voluntad a través de la nuncupatio y cinco testigos. En cualquier caso, el derecho romano consideraba indispensable el nombramiento de heredero heredis institutio-, hasta el punto de condicionar la validez del acto a la inclusión o no de esta cláusula.

\section{3. Época postclásica justinianea:}

Sin alterar en lo sustancial la concepción del testamento expuesta, el Derecho sucesorio ofrece ya prácticamente las mismas características que pasarán a los códigos modernos a través de la recepción del Derecho común en la plena Edad Media, y limita su aportación al enriquecimiento de aquel instrumento jurídico -que, en consonancia con ese supuesto anterior, es lógicamente el recibido por esa vía en Occidente-, con la aparición de reformas formales que afectan a las modalidades testamentarias -distinción del testamento privado y público- hasta completar casi en su totalidad las ya conocidas: 
Como sabemos, el privado requería la presencia de siete testigos rogados, voluntarios y capacitados, realizándose el otorgamiento en un mismo acto y sin interrupción; podía hacerse oralmente -siendo escuchado por los testigos- $y$ por escrito, al presentar el testador ante aquéllos el documento que contenía sus últimas disposiciones y que, a su vez, podía ser ológrafo, si lo habría escrito el mismo otorgante, o alógrafo, si había sido escrito por otra persona, aunque, en ambos casos, la suscripción de los testigos era imprescindible. El público, cuya exposición era siempre oral, podía también adoptar dos formas, siendo la primera la que se otorgaba ante la autoridad judicial, que recogía en un acta las palabras del testador, y la segunda, la que se entregaba por escrito para ser custodiada en los archivos imperiales ${ }^{43}$.

\section{Aparición del Cristianismo:}

Abogó por el testamento en favor de iglesias, hasta conseguir posteriormente que esta presión originara la conformación de su estructura con la inclusión de unas cláusulas de contenido religioso y la consolidación de una costumbre -por no decir obligación-, tendente a que el testador dejara una porción de sus bienes a ciertas instituciones eclesiásticas para salvación de su alma.

\section{Primera época del derecho germánico:}

Sin olvidar el concepto de testamento como declaración de última voluntad para después de la muerte, el testamento romanovisigodo empieza a alterar algunos de los trazos clásicos del documento -por ejemplo, la institución de heredero, que inicia su inclusión en los codicilos, pero deja de considerarse esencial para la validez y fundamentación del testamento hasta su total inobservancia en el siglo VI- y. se consolida la relajación o flexibilización de las solemnidades exigidas, fenómeno que se manifiesta en la pluralidad de testamentos y en la aparición de testamentos especiales. En general, se observa una tendencia a permitir mayor libertad de expresión al otorgante, siempre que quede clara la voluntas testatoris.

\section{Etapa del último derecho visigodo:}

El Liber Iudiciorum presenta un testamento que sigue siendo en gran parte tributario del contenido en el Breviario de Alarico, en cuanto que se mantiene como un acto solemne -puede otorgarse por escrito $\mathrm{y}$, en caso necesario, oralmente ante testigos-,' sujeto a ciertos requisitos formales, y sólo tiene efecto tras la muerte del testador, aunque, prolongando la tendencia postclásica, se considera innecesaria la institución de heredero.

Por lo que respecto a la capacidad, la condición de la persona para disponer y recibir por testamento presenta continuidad con el derecho 
romano postclásico, mientras que las correcciones típicamente visigodas afectan a la clase de bienes sobre los que se puede testar, cuota de libre disposición, mejoras, etc. Esta preocupación de la última legislación visigoda por las cuantías de las disposiciones, que no debían sobrepasar ciertos límites, hace que el testamento acabe sirviendo tan sólo para mejorar o disponer del quinto libre -llamado también, como veremos, quinto del alma o cuota pro ánima-, a excepción, claro está, de aquellos casos en que no existieran hijos, que permitían la ampliación de esa parte de libre disposición.

\section{Alta Edad Media:}

Aunque el testamento visigodo, heredero, a su vez, del romano si bien con las modificaciones analizadas, sigue persistiendo en algunas zonas caso, verbigracia, de Cataluña-, precisamente porque para disponer del "quinto libre" bastaba la donación, en esta época se observa una crisis del testamento -confundido quizás con la donatio mortis causa-, que corre paralela al triunfo de la sucesión legítima no testamentaria. Esta fórmula jurídica permite la aparición de otros negocios de disposición mortis causa y la configuración del testamento, cuyo vocablo clásico -testamentumadquiere en esta etapa nuevas significaciones que, en algunos casos, nada tiene que ver con las declaraciones de última voluntad, sino que designa a todo documento que contuviera cualquier tipo de negocio jurídico, como una especie de mandato, que no necesita institución de heredero, y por cuya virtud se encarga a un cabezalero, manumissor o albacea el reparto de los bienes de la herencia y el pago de las deudas.

\section{Plena Edad Media:}

Etapa crucial para la revalorización del testamento en la misma efervescencia cultural de la corte castellana del "rey legislador", que permite la recuperación de la tradición postclásica $y$, sobre todo, justinianea.

Con la recepción del ius commune, reaparece el testamentum romano. En la más pura línea de continuidad con esta última doctrina, el término utilizado por el Derecho clásico romano y transmitido a las lenguas románicas es el de testamentum, cuyo concepto es desarrollado por Alfonso $X$ en la VI Partida como acto solemne de la manifestación de la voluntad de un individuo acerca de la suerte que afecte a sus bienes, derechos, obligaciones y toda clase de disposiciones para después de su muerte; y como acto jurídico dotado de naturaleza propia por la incorporación de garantías legales suficientes y sujetos testamentarios integrantes de su constitución. Las Partidas, por tanto, no sólo recuperan el ya conocido contenido de ese concepto y la variedad de distintas modalidades testamentarias, sino también la necesidad de la institución de heredero y el principio de sucesión universal ${ }^{44}$. 


\section{Baja Edad Media:}

La modificación más significativa procede del Ordenamiento de Alcalá de 1348, cuyo título $\mathrm{XX}$ deroga el último principio antes mencionado, declarando que "[...]el testamento sea valedero en las demandas, e en las otras cosas, que en él se contienen, aunque el testador non aya fecho heredero alguno" ${ }^{45}$, e inicia una etapa de confusión sobre si era o no necesaria la institución de heredero en testamento para su validación, zanjada con el reconocimiento de que ese nombramiento no es fundamental para la plena validez del documento de última voluntad. Como sabemos, esta posición permanece inalterable al paso del tiempo, como demuestra el último gran ordenamiento jurídico del Antiguo Régimen $^{46}$, y la misma y directa práctica social: María de Pedrajas y Francisco Sánchez y Campos testaron sin designar herederos, y sus otorgamientos fueron plenamente autentificados y protocolizados ${ }^{47}$.

\section{Edad Moderna:}

Terminada prácticamente la tarea de diseñar los perfiles esenciales del testamento, la intervención legislativa de esta época se limita a la regulación de ciertos legados, cuya consideración es importante por el peso de su contenido religioso, y a la aclaración de temas muy concretos relacionados con la sucesión testamentaria.

En el primer sentido, nos referimos fundamentalmente a las mandas piadosas de obligado cumplimiento, conocidas justamente por eso también como mandas pías forzosas, gestos que, fundamentados probablemente en las mencionadas "cuotas pro ánima" medievales aplicadas por el bien del alma del difunto, pasaron a ser obligatorias merced a la gestión de los legisladores modernos en esa dirección: La pragmática de Felipe IV del once de febrero de mil seiscientos veintitrés establecía la necesidad de dejar en los testamentos alguna cantidad para casar mujeres huérfanas y pobres, y las posteriores actualizaciones del once de diciembre de mil setecientos cincuenta y de diecisiete de octubre del año siguiente, se orientaron a recaudar fondos con destino a conservación de los Santos Lugares y redención de cristianos cautivos, y aun a socorrer a la Corona en situaciones muy concretas, colaboración que ya tuvo concreción local ${ }^{48}$.

En cuanto a la tarea de matización, nos referimos, entre otras, a cuestiones tales como solemnidades requeridas para cada tipo de testamento, regulación del otorgado por comisario, testación activa del condenado a muerte, testamentarías, etc.

Como hemos visto, parece innegable la responsabilidad del tiempo y la historia en la conformación de la práctica testamentaria. Avatares de muy distinto signo y carácter colaboraron en la construcción y constitución 
de la naturaleza del testamento; influyeron en la dinámica histórica de su concepto, cuyo más llamativo resultado afectó a la definición formal y estructural del documento de última voluntad, reflejada, por un lado, en la capacidad de disponer de bienes materiales, y, por otro, en su connotación religiosa por la reserva de una porción para el alma, ejes simbólicos de la estrecha convivencia mantenida entre contenidos patrimoniales $y$ espirituales expresados en cláusulas declaratorias y decisorias, y sin la cual es imposible comprender el testamento del Antiguo Régimen; e incidieron en la atribución de un sentido propio a ese instrumento notarial, en cuyo desciframiento han participado distintas doctrinas jurídicas como ahora señalamos.

\section{INTERPRETACIONES JURIDICAS.}

A toda esa trayectoria no le ha sido ajeno tampoco el debate historiográfico e interpretativo, uno de cuyos contenidos resulta del máximo interés por cuanto afecta, de plano y de pleno además, al concepto y sobre todo al sentido del testamento del Antiguo Régimen, y en el que, precisamente por eso, nos vamos en aquél a detener.

Tratando de entender las múltiples influencias que, entrelazadas a lo largo del tiempo, cooperaron en la elaboración de la noción de testamento analizada; la participación de cada regulación jurídica en el desarrollo histórico del documento de última voluntad; las modificaciones que en su estructura introdujeron; la filosofía que respaldó la consolidación de sus distintas partes; y especialmente las motivaciones que justificaron la connotación espiritual del testamento medieval y moderno por la reserva de una cantidad del caudal para hacer bien por el alma del causante, se han dado varias explicaciones que atienden a otras tantas líneas interpretativas evolutivas.

Dejando al margen la clásica, formada por quienes defienden la ya conocida e indiscutida colaboración del derecho hereditario romano en la definición y consolidación del acto de otorgamiento, la mayor parte de los juristas se inclinan por defender el peso de las costumbres sucesorias de los pueblos invasores o la aportación del fenómeno de la cristianización en el proceso de construcción de la práctica testamentaria, posturas ambas que cuajan en la diferenciación de sendas tendencias germánica y canónica.

Es evidente también que al plantear este tipo de cuestiones, las distancias son más teóricas que reales, y se producen a la hora de marcar cada autor la dispar contribución de cada influencia en la construcción del concepto y estructura del testamento. Precisamente porque ambas líneas argumentales no resultan necesariamente unívocas ni contrapuestas, sino todo lo contrario -por efecto de la propia dinámica histórica, las respectivas aportaciones teóricas que las sustentan se implicaron ampliamente entre sí-, 
parece conveniente que, sin eludir las peculiaridades de cada línea, optemos por la presentación de una visión de conjunto ${ }^{49}$.

Frente a la defensa de los intereses del individuo y de la propiedad individual atribuida al marco jurídico romano, el derecho hereditario germánico pone su acento en la comunidad y en la salvaguarda de los bienes de la familia, a la que considera sujeto principal de relaciones jurídicas. En dicho ordenamiento los bienes familiares quedan adscritos a la propiedad mancomunada que no admite otra sucesión que la legítima. La familia germánica responde a la cohesión de grupo familiar y de este carácter se deriva la ligazón de la herencia a esa institución. Esta realidad explica el que las disposiciones de última voluntad fueran desconocidas en el derecho germánico. El padre no tenía bienes propios, sino que todos los miembros de la familia eran copartícipes. En este sentido, la muerte del cabeza de familia provocaba la vinculación de los bienes a otros miembros familiares -hijos y, en su defecto, nietos-. Ahora bien, de esta propiedad familiar se desgajaba una pequeña fracción con la proporción del patrimonio denominada Totenteil o parte o equipaje del difunto -ajuar compuesto de objetos de uso personal como trajes, armas, caballos y medios de sustento-, que correspondía justamente al muerto como bagaje indispensable para poder realizar su viaje eterno.

Para H. Brunner ${ }^{50}$, esta porción detraída del patrimonio familiar en concepto de "equipo del muerto" sufrirá el influjo del Cristianismo, que pretenderá la transformación de dicha parte en cuota pro ánima mediante la entrega del equivalente monetario del ajuar del difunto a la institución eclesiástica donde se le entierre para que haga sufragios por el bien de su alma. El planteamiento de Brunner, ha suscitado, empero, algunas disensiones, referidas no sólo a la evolución del derecho hereditario germánico en su encuentro con el Cristianismo, sino también a su interpretación sobre la aportación de San Agustín al origen de la parte de libre disposición.

Así la de J. A. Infantes Florido, para quien la de aquél es una interpretación interesada de esta cuestión ${ }^{51}$; o la de también A.Schultze, quien sostiene que, si bien existía el concepto de unidad patrimonial germánica que aseguraba la herencia por igual a los herederos legítimos, no obstante, cuando se producía la emancipación de los hijos, se efectuaba una partición de la propiedad entre ellos, reservándose el padre una parte de los bienes para la subsistencia de la madre, hijas solteras y la suya propia ${ }^{52}$. A juicio asimismo de L. García de Valdeavellano ${ }^{53}$, la posición de Schultze ha venido igualmente a señalar nuevos puntos de vista y a rectificar la relación causal que observaba Brunner entre la Totenteil y la cuota de libre disposición ${ }^{54}$.

Este carácter primitivo de convenio entre padres e hijos a propósito de la partición y participación en el haber familiar, desaparece en la época 
franca en que la secesión de cuotas se presenta como una facultad unilateral del padre, incluso contra la voluntad de los hijos, de donde resulta la necesidad de una medida de división fija y exacta -tertia de los derechos franco, anglosajón y anglonormando; o división pro capite de borgoñones, alemanes y oeste escandinavo ${ }^{55}$, , que el Derecho visigodo español estableció en una quinta parte de los bienes ${ }^{56}$.

El último eslabón del proceso sería la asignación al cabeza de familia de la parte correspondiente a la cuota fijada de los bienes vinculados patrimoniales y la separación de esa parte sobre la que podría disponer libremente -cuota de libre disposición-. Según Schultze, tal separación es resultado de la libertad de testar propia del derecho romano aún vigente en asentamientos con población mixta -es decir, un encuentro entre sociedades marcadas por el derecho romano y dominadas también por el germánico visigodo-, y, sobre todo -aunque esta idea no es compartida por otros juristas-, de la gestión realizada por la Iglesia cristiana primitiva de Occidente, que persiguió la transformación de esa parte de libre disposición en cuota por ánima, ya absoluta, como quería Salviano, ya en la parte de un hijo, como pedía San Agustín, mas, en todo caso, favoreciendo así donaciones en su beneficio para lograr la salvación ${ }^{57}$.

En ese panorama, del que evidentemente -y en términos generalesparticipa, aparece el caso español, en donde la aplicación de esa evolución reviste fisonomía especial por las peculiares características de nuestras circunstancias políticas medievales. De ahí que, aun cuando también en nuestra historia jurídica hallamos la consagración de la cuota libre en la cuantía de una quinta parte del patrimonio como sabemos -y aun como institución de vigencia contrastada durante varios siglos-, las soluciones dadas por la interpretación de Schultze no pueden ser absolutamente satisfactorias $^{58}$. El estudio del ordenamiento visigótico hispánico -leyes $S i$ mulier a marito de Leovigildo y Dum Inlícita de Chindasvinto, sobre todo-, ciertos diplomas de la Alta Edad Media -asturleoneses en concreto-, y regulación posterior de la cuota libre reflejada en los fueros municipales y alguna redacción del Derecho territorial, lleva a García de Valdeavellano a tres deducciones claras para el caso hispánico ${ }^{59}$ :

1. Existencia de dos momentos -y en consecuencia dos sentidos y praxis- en la atribución del quinto de libre disposición a la iglesia -y por ende su conversión en cuota pro anima- claramente establecidos y diferenciados: El dominio visigodo, cuyo ordenamiento ampara una verdadera cuota de libre disposición en favor de quien se quisiera; el periodo cristiano posterior, donde la atribución del quinto en favor de institutos eclesiásticos es casi ya total. En la Baja Edad Media la consagración de la quinta como cuota exclusiva pro anima es ya absolutamente normal, lo que significa que la auténtica tradición legal visigoda del aut quibus elegerint se ha perdido ya completamente. 
2. Tal consagración de la quinta visigoda no puede imputarse por completo al influjo eclesiástico, sino a la tradición romana, porque la intervención de la Iglesia se realizó sólo más tarde, mediante la aplicación de la lex gótica restringida a las ecclesiis, obteniendo en la práctica la dedicación única de la quinta pro remedium animae.

3. La razón de que aquella genuina tradición visigoda se extinguiera se debió al triunfo del germanismo' en el derecho altomedieval y a la extensión cada vez más amplia de esa tendencia en la concepción jurídica que vehiculan los diplomas medievales. Se produjo así un retroceso en la praxis consuetudinaria de la libre disposición, patente en el carácter casi único de cuota pro ánima que la quinta visigótica adquirió por injerencia eclesiástica, hasta conseguir que esa adjudicación se implantara como norma absolutamente general en los distintos fueros municipales.

Coincidiendo en lo fundamental con las posiciones teóricas del jurista anterior sobre la evolución del quinto de libre disposición e influencia de la iglesia para desviar su cuantía en favor del alma, Maldonado y Fernández del Torco piensa, por su parte, que el factor decisivo de tal transformación radicó en las especiales circunstancias religiosas, bélicas y económicas de la Reconquista ${ }^{60}$.

Sea como fuere, lo importante, como anunciamos al principio, es que el fundamento de esa práctica de dejar bienes pro ánima para después de la muerte se halla en el reconocimiento social de realizar una obra meritoria a través de liberalidades piadosas para obtener un fin religioso; que esta corriente contribuyó a que los difuntos hicieran concesiones de parte de sus bienes a instituciones eclesiásticas, beneficiando así a la propia alma; y que se fue produciendo la asunción de aquella tendencia en distintos instrumentos de sujeción y control como: Fueros Municipales, redacciones medievales, ordenamiento plenomedieval con la ya conocida recepción del derecho común, regulación jurídica posterior y ampliaciones complementarias modernas, hasta llegar a la Novísima Recopilación, hechos jurídicos todos ellos de primera magnitud e importante fecundidad para el desarrollo de las instituciones de Derecho privado y la explicación y comprensión de la concepción del testamento como documento esencialmente religioso en la Época Moderna. Se culminaba además así toda una trayectoria y tarea, de manera que si quizás al principio fue aquella dejación una costumbre popular voluntaria ${ }^{61}$, pasó a constituirse en práctica general que, al asumirse en el Derecho canónico ${ }^{62}$, 'será posteriormente impuesta con carácter obligatorio ${ }^{63}$. 


\section{CONSIDERACIONES FINALES}

Para terminar, cierta recapitulación. A modo de ésta -y desgajado de todo lo anterior-, destacaríamos lo siguiente:

Vinculación desde el principio y para siempre del origen del concepto de testamento a la acumulación de un patrimonio, a la posibilidad de disponer, y ésta de la expresa y explícita voluntad del otorgante.

Concurrencia de múltiples acciones, aportaciones e influencias en el Occidente europeo, de cuya intervención deviene el testamento como producto esencialmente histórico.

Existencia de varias líneas interpretativas sobre la constitución y conformación de aquél, en donde no pocas veces -por no decir siempre-se han encontrado Iglesia y Estado, también en múltiples ocasiones apoyada y amparada la primera por el segundo.

Destacada participación, en fin, de la Iglesia en la apropiación del quinto de libre disposición, ya por motivaciones político-bélicas, económicas o religiosas, de donde resultó el peculiar sentido eminentemente espiritual, cuasi sacramental, del documento de última voluntad del Antiguo Régimen ${ }^{64}$.

\section{NOTAS.}

1 Rugiero: Apud.: Castán Tobeñas, J., Derecho Civil Español, Común y Foral, VI: Derecho de Sucesiones, $2^{\circ}$ : Los particulares regímenes sucesorios. La sucesión testamentaria. La sucesión forzosa, Madrid, $1978^{8}$, p. 14.

2 Arias Ramos, J., Derecho Romano, II, Madrid, 1972, p. 761: Apud.: Reder Gadow, M., Morir en Málaga. Testamentos malagueños del siglo XVIII, Málaga, 1986, p. 5. La autora sigue indicando que, si bien para algunos jurisconsultos de la Edad Moderna el testamento tenía que ser necesariamente de Derecho Natural por estimar que una institución tan antigua no podía tener otra procedencia, otros, por el contrario, desde el surgimiento de la escuela histórica del Derecho, lo consideraron un producto histórico adscrito al Derecho Civil, ya que la facultad de testar afecta tanto a los intereses del testador como a los de los herederos, y repercute, en general, sobre toda la sociedad.

3 Pascua Sánchez, $\mathbf{M}^{\mathrm{a}}$ J. de la, Vivir la muerte en el Cádiz del Setecientos (1675-1801), Cádiz, 1990, p. 91. 
4. Ferrando, R., Todo sobre sucesiones y testamentos, Barcelona, 1985, pp. 30-1.

5 Castán Tobeñas, J., Op. cit., p. 15.

6 Digesto, lib. XXVIII, tít. I, fragmento $1^{\circ}$ : Apud.: Castán Tobeñas, J., Op. cit., p. 15: Testamento es el exacto cumplimiento de nuestra voluntad en aquello que cada uno desea que se haga después de su muerte.

7 Castán Tobeñas, J., Opp. cit., p. 16.

8 Tít. III -De las sucesiones-, Cap ${ }^{\circ}$ I -De los testamentos-, Sección $2^{\mathrm{a}}$ De los testamentos en general-: Código Civil, Madrid, $1991^{14}$, p. 257. $\mathrm{El} \operatorname{art}^{\circ} 668$ incide precisamente en la polémica validación jurídica del testamento con la necesaria o no institución expresa de heredero, ya que reconoce que el testador puede disponer de sus bienes a título de herencia o de legado, exponiendo que "en la duda, aunque el testador no haya usado materialmente la palabra heredero, si su voluntad está clara acerca de este concepto, valdrá la disposición como hecha a título universal o de herencia": Ibíd.; subrayado nuestro.

9 Castán Tobeñas, J., Op. cit., p. 16.

$10 \quad \operatorname{Art}^{\circ} 667$, Código..., p. 257.

$11 \mathrm{Art}^{\circ}$ 669, Código..., p. 258: "No podrán testar dos o más personas mancomunadamente, o en un mismo instrumento, ya lo hagan en provecho recíproco, ya en beneficio de un tercero".

$12 \mathrm{Art}^{\circ} 670$, Código..., p. 258. Sigue también así: "Tampoco podrá dejarse al arbitrio de un tercero la subsistencia del nombramiento de herederos o legatarios, ni la designación de las porciones en que hayan de suceder cuando sean instituidos nominalmente".

Art 673 , Código..., p. 258.

$14 \quad$ Art $^{\circ} 687$, Ibíd., p. 261.

$15 \quad \mathrm{Art}^{\circ} 737$, Código..., p. 273.

16 Castán Tobeñas, J., Op. cit., pp. 22-7. Combinando todos esos elementos y pasando del análisis interpretativo al examen directo del corpus jurídico, las formas de testar admitidas actualmente en el Derecho común y recogidas en el Código civil son: 
Testamentos COMUNES ORDINARIOS (art ${ }^{\circ} 676$ ): Ológrafo $\left(\operatorname{art}^{\circ}\right.$ 678), Abierto ( $\operatorname{art}^{\circ} 679$ ), Cerrado (art ${ }^{\circ} 680$ ).

COMUNES EXTRAORDINARIOS O EXCEPCIONALES: Del loco lúcido ( $\operatorname{art}^{\circ} 665$ ), Del enteramente sordo (art ${ }^{\circ} 697$ ), Del ciego (art ${ }^{\circ} 698$ ), Del mudo y del sordomudo (art ${ }^{\circ} 709$ ), Otorgado en lengua extranjera (art's 684, 688), Otorgado en peligro de muerte (art 700 ), Otorgado en tiempo de epidemia (art ${ }^{\circ} 701$ ).

ESPECIALES ( $\operatorname{art}^{\circ}$ 677): Militar: Ordinario -en campaña-: Abierto (art 716), cerrado -ante los comisarios de guerra (art $\left.{ }^{\circ} 717\right)$-. Extraordinario en peligro militar-: Abierto ( $\operatorname{art}^{\circ} 720$ ), cerrado ( $\operatorname{art}^{\circ} 721$ ). Marítimo: Ordinario -a bordo: Abierto (art ${ }^{\circ}$ 722), cerrado (art ${ }^{\circ}$ 722)-. Extraordinario -en peligro de naufragio (art ${ }^{\circ} 731$ )-. Hecho en país extranjero: Conforme a la ley territorial (art ${ }^{\circ} 732$ ). Ante funcionarios diplomáticos o consulares (art ${ }^{\circ} 734$ ). Otro significativo resumen en A. Cicu, El Testamento, Madrid, 1959, pp. 51-2.

17 Castán Tobeñas, J., Op. cit., pp. 83-100. Espín Cánovas, D., Manual de Derecho Civil Español, V: Sucesiones, Madrid, $1978^{5}$, pp. 251-261, 263-270. Ferrando, R., Todo sobre..., pp. 11-53.

$18 \quad \operatorname{Art}^{\circ} 679$, p. 259.

$19 \quad \mathrm{Art}^{\circ}$ 694, Código..., p. 263.

Espín Cánovas, D., Op. cit., pp. 265-6.

21 Martínez Pereda, M., "Reflexiones jurídicas sobre la llamada sucesión a favor del alma", Anales de la Academia Matritense del Notariado, VII (1953), p. 171.

Código..., pp. 274-5.

23 Código..., p. 275.

24 Castán Tobeñas, J., Op. cit., p. 91. A la forma oral del otorgamiento se refiere específicamente el art ${ }^{\circ} 695$ del Código civil, edic. cit., p. 263.

25 Espín Cánovas, D., Op. cit., pp. 267-8.

$26 \quad \mathrm{Art}^{\circ} 695$, p. 263.

$27 \mathrm{Art}^{\circ} 695$, apd $^{\circ} 3$.

28 Ferrando, R., Todo sobre..., pp. 17-8. 
$29 \mathrm{Art}^{\circ} \mathrm{s} 695,696$

30 Ferrando, R., Todo sobre..., pp. 15-7.

$31 \operatorname{Art}^{\circ} 695$, apd $^{\circ}$ s. 1 y 2.

32

Art $^{\circ}$ 699, apdo. 1, p. 264.

33

Espín Cánovas, D., Op. cit., p. 268.

34 Arce y Cervantes, J., "Reflexión sobre el testamento", Anales de la Academia Matritense del Notariado, XXII, $2^{\circ}$ (1981), p. 544. Sobre la regulación del Código de esos elementos técnicos del testamento contemporáneo, especialmente ejecutores testamentarios, perceptores de bienes y porción partible (concepto, distribución y cálculo de legítimas y mejoras):Ferrando, R., Todo sobre..., pp.28-63, 66-76. También muy útil la síntesis de M. Reder Gadow, Morir en..., pp.27-54.

35 Reder Gadow, M., Op. cit., pp. 5 y ss. Artola, M. (dir.), Enciclopedia de Historia de España, V: Diccionario Temático, Madrid, 1991, pp. 1.147 y ss. Castán Tobeñas, J., Op. cit., pp. 84 y ss. González Porras, J. M., Comentarios al Código Civil y Compilaciones Forales, IX, $1^{\circ}-\mathrm{B}$, Madrid, 1987, pp. 6 y ss., sobre todo.

36 Castán Tobeñas, J., Op. cit., pp. 84-5.

37 Reder Gadow, M., Op. cit., p. 17. González Porras, J. M., Op. cit., p. 3.

38 López Fando, J. M., Prontuario de Testamentos y Contratos, I, Madrid, 1798, p. 30.

39. Cicu, A., Op. cit., p. 86.

40 Código o estudios fundamentales sobre el Derecho Civil español, II, Madrid, 1871, p. 114: Apud.: Reder Gadow, M., Op. cit., p. 5, n. 2.

41 Reder Gadow, M., Op. cit., pp. 7-8.

42 Sin que sirva en nuestro descargo, no abundan las elaboraciones históricas sobre evolución del testamento realizadas por juristas, salvo honrosas excepciones -Albadalejo García, M. et alii, Comentarios al Código Civil y Compilaciones Forales, X, 10, Madrid, 1987, 425; Comentarios al Código Civil y Compilaciones Forales, X, $1^{\circ}-\mathrm{A}$, Madrid, 1990, 484. Iglesias, J., Derecho romano: Instituciones de derecho privado, Barcelona, 1987, 774. Lalinde Abadía, J., Iniciación histórica al Derecho español: instituciones político-administrativas y civiles, Barcelona, 1989, 475. Pérez de Benavides, M., El testamento 
visigótico: una contribución al estudio del derecho romano vulgar, Granada, 1978, 164-, y tampoco los historiadores de la muerte han abordado con entusiasmo la reconstrucción de esta cuestión. De ahí, que hayan sido muy escasas las fuentes disponibles para cumplir este cometido. Junto a las anteriores, dos básicamente, la de Reder Gadow, Op. cit., pp. 5-7, 27-41; y la de Artola, Op. cit., pp. 1.147-9.

43 Reder Gadow, M., Op. cit., p. 8.

44 Fundamentalmente Partida VI, 1, 3; 1, 2; 3,1: Apud.: Albadalejo García, M. et alii, Comentarios al..., X, $1^{\circ}-\mathrm{A}$, p. 70 y ss.

Albadalejo García, M. et alii, Comentarios al..., X, $1^{\circ}$, p. 316.

Novísima Recopilación, 10, 18, 1.

47 Archivo de Protocolos Notariales de Córdoba, hoy inserto en el Archivo Histórico Provincial, oficio 18, protocolo 157 (1720), 178-179v.; oficio 19 , protocolo 192 (1770), 114-115v., respectivamente.

Maldonado y Fernández del Torco, J., Herencias en favor del alma en el derecho español, Madrid, 1944, pp. 166-7.

Reder Gadow, M., Op. cit., pp. 8-13.

50 Der Totenteil in germanischen Rechten, Weimar, 1880, pp. 107-139: Apud.: Reder Gadow, M., Op. cit., p. 8, n. 11.

"San Agustín y la cuota de libre disposición", Anuario de Historia del Derecho Español, XXX (1960), pp. 89-112.

52 Augustin und der Seelteil des germanischen Erbrechts, Leipzig, 1928, p. 6: Apud.: Reder Gadow, M., Op. cit., p.9, n. 13.

53 "La cuota de libre disposición en el derecho hereditario de León y Castilla en la Alta Edad Media. (Notas y Documentos)", Anuario de Historia del Derecho Español, IX (1932), pp. 129-176.

Ibíd., p. 134.

55 García de Valdeavellano, L., "La cuota de...", p. 135.

56 García de Valdeavellano, L., Op. cit., pp. 138-9.

57 García de Valdeavellano, L, Op. cit., p. 136, interpretando el pensamiento del alemán, para quien la influencia eclesiástica fue el verdadero factor genético, especialmente en los sermones agustinianos, 
de esa cuota de libre disposición del derecho visigodo y de su derivación en pro del alma.

58 García de Valdeavellano, L., Op. cit., pp. 137-8.

59 Op. cit. pp. 141-157.

60 Herencias en favor del..., pp. 45-6.

61 Rubio Rodríguez, J. J., Las fundaciones benéfico-religiosas en el Derecho común y español, I: Estudio histórico-jurídico, Córdoba, 1985, pp. 74-9.

62 Cance, A.; Arquer, M. de, El Código de derecho canónico. Comentario completo y práctico de todos sus cánones para uso de eclesiásticos y hombres de leyes, I, Barcelona, 1934, pp. 950-5.

63 Maldonado y Fernández del Torco, M., Op. cit., p. 118.

64 García-Gallo,A.,"Del testamento romano al medieval.Las líneas de su evolución en España",Anuario de Historia del Derecho Español, XLVII (1977),425-497. Murga Gener, J.L., "El testamento en favor de Jesucristo y de los santos en el derecho romano postclásico y justiniano", Anuario de Historia del Derecho Español, XXXV (1965), 356-419. Rubio Rodríguez, J.J., Las causas pías en los juristas clásicos españoles de los siglos XV al XVII (Estudio histórico-jurídico), Sevilla, 1976, 41. 